\title{
The Mechanix Behind the Circulation of Low Quality Music Offerings in a Digital World
}

\section{Deepak Paul}

Research Scholar, VIT University

Xavier M. J

The Executive Director, VIT University

Pulidindi Venugopal

Associate Professor, VIT University

Doi:10.5901/mjss.2016.v7n2s1p400

\begin{abstract}
The digital world has accorded rookies and established artists with an unprecedented ability to circulate their low quality music offerings. They are now able to interact with fans directly, crowdsource, co-create, showcase and monetize their content. This paper intends to explain the mechanics behind the circulation of such offerings through the ever-mutating digital medium.
\end{abstract}

Keywords: Low quality music, Digitalization, Music circulation, Bit rate, Windowing

\section{Introduction - Low Quality Music Offerings}

Bit rate refers to the number of bits or the amount of data that is contained in one second of audio. Let's just take the example of a $320 \mathrm{kbps} \mathrm{mp3}$ audio file. $320 \mathrm{kbps}$ means 320 kilobits of data is stored in every second of a song. So, if the bit rate is higher it will take up more space on the hard drive and to save space the bit rate is reduced which leads us to the contentious issue of lossy and lossless formats. Lossless format means there is no compression of an audio file ripped from the original $C D$. That is, the information of the ripped file and the source file contained in the original $C D$ are similar. An album ripped in lossy or compressed formats like $m p 3^{1}, A A C^{2}, W M A^{3}$ would have a file size of about a $100 \mathrm{mb}$ or lesser. But, the same album in lossless formats like FLAC ${ }^{4}$ or $A L A C^{5}$ would take up to about $300 \mathrm{mb}$ or much more. Lossless formats are popular because of their lower space requirements which translate into faster download and transfer of files across the internet. There are different levels of lossiness like $96 \mathrm{kbps}, 128 \mathrm{kbps}, 160 \mathrm{kbps}, 192 \mathrm{kbps}, 224 \mathrm{kbps}$, 320 kbps et cetera.

The audible range of a human ear is $20 \mathrm{~Hz}-20 \mathrm{KHz}$. According to Nyquist theorem, the sampling rate used to encode sound should be twice the highest frequency perceived by the human ear. That's why the sampling rate used for encoding is $44.1 \mathrm{KHz}$ (Almost twice) or 44,100 measurements of the waveform's amplitude per second. CD-quality audio uses 16 binary digits to represent the amplitude value of each measurement, or sample.

Bit rate $=16$ (bits) $\times 44,100$ (fs) $\times 2$ (two channels in a stereo signal) $=1411.2 \mathrm{kbps}$

Reduction in quality $=\{(1411.2-128) \mathrm{kbps} / 1411.2 \mathrm{kbps}\} * 100 \sim 90 \%$

As mentioned earlier, information is lost when a sound signal is encoded at a lower bit rate. The bit rate of a CDquality audio is $1411 \mathrm{kbps}$ but an mp3 is $320 \mathrm{kbps}$ tops. There is approximately a 90 percent reduction in music quality. Greater the bit rate, greater the information stored in an audio signal per second.

"Remember that the bit rate for uncompressed, $C D$-quality audio is $1411 \mathrm{kbps}$. The goal of mp3 was to produce acceptable results at $128 \mathrm{kbps}$. That is a data reduction of close to 90 percent, producing a file about 11th the size of

\footnotetext{
1 Stands for MPEG audio layer III and is a highly compressed audio file which requires lower digital storage and enables faster transmission

${ }^{2}$ Advanced audio codec

3 Windows media audio

${ }^{4}$ Free lossless audio codec

${ }^{5}$ Apple's lossless audio codec
} 
the raw 16-bit, $44.1 \mathrm{kHz}$ PCM file. This is undeniably an achievement in terms of audio quality versus bit rate, but unfortunately, many side-effects are present and audible at this bit rate. Though higher bit rates result in less information being discarded and fewer undesirable sonic artifacts, fewer songs will fit into the same storage space (lan Corbett, 2011)." The researcher has used 'Bit rate' and 'lower file sizes' as the basis on which a music offering is termed 'Low quality'.

\title{
2. Objectives of the Study
}

1. To study about some of the ways in which low-quality music is being circulated

2. To understand the effect of digitalization on low-quality music circulation

\section{Youtube Effect}

"YouTube has become the third most visited website in the world behind Google and Facebook. Since its creation in 2005, YouTube saw rapid growth; sixteen months after its creation, 100 million clips were being viewed per day. In 2008, the site attracted 100 million American viewers a day, estimated to be over two thirds of the internet users in the United States (comScore, 2008)."

\begin{abstract}
"Teenagers evidently do not see computers as technology. It's as if they've developed an innate ability for textmessaging, gaming, iPodding and multi-tasking on multiple platforms. They can share their story on Facebook, entertain each other on YouTube, muse philosophically in the blogosphere, contribute to knowledge on Wikipedia, create cuttingedge art on Flickr, and compile archives on Del.icio.us (Hartley, 2009)." "The interactive culture created on the internet had made a social link between people who have never met face to face. These new technologies have enabled the internet to become an interactive media technology, allowing art to be consumed, created and shared like never before (Jenkins, 2006)." "YouTube is more a social network site than a video sharing site. It allows performers to have a global audience (Lange, 2008)."
\end{abstract}

YouTube serves as a virtual coffee house where people can share ideas and gather with like-minded and contrasting individuals to discuss ideas, music, and art. It allows many bedroom musicians to produce their craft to audiences. The infinite possibilities of this video sharing virtual world are only bound by the imaginations of the users, the terms of service of the web-space provider and sometimes a fire wall.

\section{Windowing}

Radiohead is a British rock band formed in the year 1985. It had signed a six-album recording contract with $E M{ }^{6}$ in the year 1991. Upon completion of the contract, the band backed-off from EMI citing lack of control over their catalogue. This means EMI gets to control the band's six albums for a period of 50 years as per copyright law. Further, they were also upset over the record company's continual deduction of packaging costs from royalty payments on digital downloads which never required any packaging. Also, they never received any royalty payments through sales from Apple's iTunes store. All these factors led to the band's departure from EMI.

Later, the band started work on their 7th album called In Rainbows and released it in the year 2007, this time as a $10 \times 160 \mathrm{kbps} 48.4 \mathrm{mb} D R M^{7}$-free digital MP3s download, where the consumer decides the price starting at literally nothing. That is fans could pre-order In Rainbows for a price they think is right, with zero as an option. Also, the mp3 download version of the album was offered with a costlier option of pre-ordering an elaborate $\$ 80$ box set of the same on vinyl record and compact disc, to be released that December. The online version of In Rainbows was released (as mp3s at $160 \mathrm{kbps}$ ) well below the industry standard of $320 \mathrm{kbps}$ and it sold 1.2 million copies at an average price of 5 pounds in the first 2 weeks. This pricing model was very unique because it bypassed the traditional model of releasing it through a major record label and consequently, a fixed price. But, by early 2008, this online version was removed and the fans were informed to purchase the In Rainbows disc box through their official website.

By employing this strategy of initially giving away an inferior version of their product for free and later on coming up with an upgraded tangible disc box at 40 pounds, Radiohead stood at a better chance to beat piracy and proliferate a participatory experience for the consumers, because the older version became obsolete. It may be too early to call this business model a success simply because the band had entered into super-stardom status only through EMl's marketing

\footnotetext{
${ }^{6} \mathrm{EMI}$ was one of the big four record companies based in England and broke-up in 2012

${ }^{7}$ Stands for Digital Rights Management, it prevents unauthorized duplication and redistribution of digital media
} 
of their earlier six albums. However, this strategy helped consumers to access their latest album at no cost, in turn enabled word-of-mouth publicity and pushed their music business from major label led mass-marketing of a static product to niche-marketing of a participatory experience.

\begin{abstract}
"Windowing means that the same film is sent through a release cycle of seven or eight windows of opportunity, from theatrical to premium channels to DVD to video to cable television to airplane movies to free-to-air television. Bands like Radiohead are now employing different models of format expansion and the associated update and replacement cycles that are used in software and film businesses. Radiohead first released the album as a $160 \mathrm{kbps} \mathrm{mp3} \mathrm{and} \mathrm{then} \mathrm{later}$ sold the same product, in a different format (CD, Vinyl). This is how the British Rock band applied the technique of windowing. Radiohead's use of different formats for the dissemination of their recorded music is reminiscent of the way in which film studios have used windowing (Kusek and Leonhard, 2005)."
\end{abstract}

"The consumer wants to get a lot more value when they purchase a DVD or a videogame. They believe that the pricing of music content online should be more flexible so that music can flow more freely and also selling physical content online is least likely to be the main method of bringing revenue to the custodians of digital music services. Recorded music has long been a static product. Rather than releasing a single unchanging album of songs and spending a huge amount marketing it, Radiohead have instead started creating products that consumers try first: then buy. Further, their product is upgradeable and they have developed an array of services and formats in which to sell their product. By employing a strategy that lets consumers purchase upgraded versions of their product, Radiohead have enabled their music to become a more fluid and participatory entertainment experience and this is where its real value lies (Kusek and Leonhard, 2005)." "The newly identified offering of experiences occurs when a company intentionally uses services as the stage and goods as props to engage an individual. Whilst commodities are fungible, goods tangible, and services intangible, experiences are memorable. Just as people have cut back on goods to spend more money on services, now they also scrutinize the time and money they spend on services to make way for more memorable and highly valued experiences (Pine and Gilmore, 1999)."

In an ever-mutating digital world, it is crucial to engage the consumer in the process of invention and price discovery rather than just selling a static product at a fixed price. We are therefore witnessing the fall of static products and the rise of Experience Economy. Through this process of Windowing, the usual top-down approach was replaced by bottom-up approach and the traditional model outmoded.

\title{
5. Research Methodology
}

The researchers have used review of literature as the basis for this research paper. Since, the goal of the authors was to expand knowledge from the theoretical point of view, a retrospective study of relevant articles were chosen. Hence, the authors felt literature review as the apt Research method.

\section{Discussion - Low Quality Music Circulation}

Online communities serve not only as discussion forums for new music, but as a space to find download links of albums, a couple of days after its release date. Mp3 blogging is a practice by which music fans link to an mp3 file and write a paragraph about the song. Of late, this has become a prominent trend, garnering enormous interest in music-based discussions and popularizing songs for reasons good or bad. The growth has largely come as a result of its natively digital format, constant updation and networked relationship to other sites that link to its reviews.

"Music bloggers had emerged a few years earlier as a heterogeneous network of mp3js, circulating music old and new, in a manner befitting only to their passions. They translate musical sounds into textual discourse and mostly operate independently. Music blogging quickly became a practice bound up in the promotional schedules of labels, especially when blogs started to be covered in mainstream magazines and music publications. Through music blogging, fandom has been translated into a scouting role for new artists, formerly the exclusive domain of labels. These labels seek to incorporate a public's identity into the promotional plans for an artist, translating music blogger discourse into a flexible promotional network, ideally capable of freely promoting new music. That's why they provide bloggers with the music, indirectly telling them to do the promotion themselves (Hennion, 1999)." "Music blogger discourse is used as autonomously produced externalities, a freely produced public communication that is redirected as promotional value for new music (Arvidsson, 2006)."

"A blog's effect on the music business is to accelerate the word-of-mouth, which used to percolate over the course of months, even years perhaps, and serve it up instantly in a flashing online warning that music lovers may be missing out 
on the next big thing (Cook, 2012)." A perspective such as Neoliberal agency leads passionate music fans to recognize their fandom as a part of a branded-self, which they leverage to form alliances with music publicists and labels. These alliances are facilitated through user-inviting blog platforms designed to embed fan-driven communication within circuits of communicative capitalism, which exploit information-age communication in the same way industrial capitalism exploited labor. Far from resisting their incorporation into these networks, music bloggers embrace their neoliberal agency and relish providing free promotion for their favorite music. "A blogger's eagerness to display their enthusiasm about ostensibly unaffiliated music was a way to getting their individual voices heard early, before it became a defining moment (Gershon, 2011)."

"Fans are but publicists, promoters, curators, and archivists. They work for free, promoting bands and labels by highlighting their music on news sites, archives and blogs. More often than not, these fans do not feel exploited, but see their work as an extension of their fandom, which is a way to communicate with their favorite artists, and help them reach the stars (Nancy Baym et al., 2009)." In the music realm, however, fan promotion is a dicey situation, with the freely performed activities of a band's most eager fans often tipping over into unsanctioned practices, such as downloading and circulating low quality music offerings like mp3s. Yet, just because practices are unsanctioned does not mean they are inherently detrimental to artists and record labels. The modularity of mp3s, the constantly changing infrastructures through which they circulate, and the affordances of the hardware or software used to play and sort them, facilitate the development of specific abilities to find and authenticate recordings outside of a market situation.

Bootlegs arose as industry insiders acquired unreleased recordings from famous artists, pressed them onto CDs, often cheaply, in the off-hours of legitimate factories and then circulated them in music stores. Bootleggers release, what the record labels would not release. Whilst record labels and artists often publicly shame bootleggers and pirates as thieves stealing from the music industry, the promotional value of these unauthorized efforts have long been tacitly accepted by the same crowd as free promotion. The rise of mp3s and their ever-mutating pathways of online circulation resulted in a dramatic expansion in the scope and practices of bootlegging and piracy. CD bootlegs were costly and risky to duplicate, lost some quality each time they were dubbed, and were sold mostly on the black market. As mp3s, music can be duplicated a zillion times at no cost to anyone with a computer, with no perceptible loss of quality and instantaneously circulated on a global scale.

As for live bootlegs, they are uploaded seconds after the concert concludes to streaming sites such as YouTube. Others upload photos and video clips of concerts taken with their smartphones to social networking platforms like Twitter and Facebook. With mp3s, the acts of bootlegging and piracy that escalated from the fringes of the recording and retail industries to an illicit industry as vinyl records and cassettes gave way to CDs became more globally dispersed and a part of fans' everyday music experiences. In the past few years, file-sharing sites like BitTorrent and file-hosting sites like Mediafire have become a platform on which songs are sought and downloaded. The major difference between mp3 leaks and pirated copies or bootlegs, is that mp3 leaks are not sold for profit. But, bootlegs are exchanged for money in illicit market exchanges that nonetheless served the same function of artist promotion as sanctioned exchanges.

\section{Conclusion}

The music industry has now shifted from working as a brick-and-mortar model to a click-and-mortar model. Online promotion of music and then selling it in the real world seems to be the best compromise at this point for most rookies and established artists here. Music has to be circulated over the web to as much number of consumers as possible. That's where low quality music with its characteristic lower bit rates and relatively lower file sizes comes in handy. These music offerings are circulated by unrestrained file-sharing, blogging and through websites like YouTube, Facebook et cetera. Radiohead's windowing strategy met with certain degree of success only after they were able to circulate their music online. Circulation has ensured the extinction of musical scarcity and made music offerings more accessible to the populace than ever.

\section{References}

Arvidsson A., (2006), "Meaning and value in media culture", European journal of communication, Vol. 22(1), pp. 99-111

comScore press release., (2008, December 9), "YouTube attracts 100 million U.S. online video viewers in October 2008", Retrieved June 29, 2009 from http://www.comscore.com/

Corbet, I., (2011, December 10), "What Data Compression Does To Your Music", Retrieved June 28th, 2014 from https://www.soundon sound.com/sos/apr12/articles/lost-in-translation.htm

Hartley, J., (2009), "Uses of YouTube: Digital literacy and the growth of knowledge", In J. Burgess \& J. Green (Eds). YouTube (pp. 126143). Polity Press: Cambridge. 
Harvey, E. (2013), "Digital Dilemmas and Promotional Possibilities: Circulating music in the late age of the mp3", ProQuest LLC.

Jenkins, H., (2006), "Convergence culture: Where old and new media collide", New York University Press: New York.

Kusek, D. and G. Leonhard (2005), "The Future of Music: Manifesto for the Digital Revolution", Boston, MA: Berklee Press.

Lange, P. G., (2008), "(Mis)conceptions about YouTube. In G. Lovink \& S. Niederer (Eds.), Video vortex reader: Responses to YouTube (pp. 87-100), Institute of Network Cultures: Amsterdam

Morrow, G., (2009), "Radiohead's managerial creativity", International journal of Research into new media technologies, Vol. 15 (2), pp. 161-176

Nancy Baym et al., (2009), "International fan labour in Swedish independent music", International Journal of Cultural Studies, Vol. 3 issue 2, pp. 45-55

Pine, J. and Gilmore, J. (1999), "The Experience Economy: Work is Theatre and Every Business a Stage", Boston, MA: Harvard Business School Press. 